\title{
Laparoscopic resection of a residual retroperitoneal tumor mass of nonseminomatous testicular germ cell tumors
}

\author{
Çiğdem Öztürk · Robert J. van Ginkel • \\ Ruby M. Krol · Jourik A. Gietema • \\ Hendrik S. Hofker $\cdot$ Harald J. Hoekstra
}

Received: 15 October 2010/Accepted: 7 July 2011/Published online: 23 September 2011

(C) The Author(s) 2011. This article is published with open access at Springerlink.com

\begin{abstract}
Background Resection of a residual retroperitoneal tumor mass (RRRTM) is standard procedure after combination chemotherapy for metastatic nonseminomatous testicular germ cell tumors (NSTGCT).

Methods At the University Medical Center Groningen, 79 consecutive patients with disseminated NSTGCT were treated with cisplatin combination chemotherapy between 2005 and 2007. Laparoscopic RRRTM was performed for patients with RRTM located less than $5 \mathrm{~cm}$ ventrally or laterally from the aorta or the vena cava. The 29 patients who fulfilled the criteria had a median age of 25 years (range, 16-59 years). The stages of disease before chemotherapy treatment according to the Royal Marsden classification were $2 \mathrm{~A}(n=6,21 \%), 2 \mathrm{~B}(n=14,48 \%)$, $2 \mathrm{C}(n=3,10 \%)$, and 4 with a lymph node status of $\mathrm{N} 2$ $(n=6,21 \%)$.

Results The median duration of laparoscopy was $198 \mathrm{~min}$ (range, 122-325 min). The median diameter of the RRTM was $21 \mathrm{~mm}$ (range, 11-47 mm). Laparoscopic resection was successful for 25 patients $(86 \%)$. Conversion was necessary for three patients (10\%): two due to bleeding and one because of obesity. One nonplanned hand-assisted procedure $(3 \%)$ also had to be performed. Histologic
\end{abstract}

Ç. Öztürk · R. J. van Ginkel · R. M. Krol ·

H. S. Hofker · H. J. Hoekstra ( $\square)$

Department of Surgical Oncology, University Medical Center

Groningen, University of Groningen, P.O. Box 30.001,

9700 RB Groningen, The Netherlands

e-mail: h.j.hoekstra@chir.umcg.nl

J. A. Gietema

Department of Medical Oncology, University Medical Center

Groningen, University of Groningen, Groningen,

The Netherlands examination of the specimens showed fibrosis or necrosis in 12 patients (41\%), mature teratoma in 16 patients $(55 \%)$, and viable tumor in 1 patient (3\%). The median hospital stay was 1 day (range, 1-6 days). During a median followup period of 47 months (29-70 months), one patient experienced an early relapse (1 month after the end of treatment) (4\%).

Conclusion For properly selected patients, laparoscopic resection of RRTM is an improvement in the combined treatment of disseminated NSTGCT and associated with a short hospital stay, minimal morbidity, rapid recovery, and a neat cosmetic result. Long-term data to prove oncologic efficacy are awaited.

Keywords Nonseminomatous - Testicular germ cell tumor $\cdot$ Residual retroperitoneal tumor mass

Treatment for nonseminomatous testicular germ cell tumors (NSTGCT) has developed enormously during the past 30 years, leading to an improved prognosis with an overall 10-year survival rate of almost $90 \%$ [1]. Disseminated disease is treated with cisplatin-based polychemotherapy that comprises three or four courses of bleomycin, etoposide, and platinum (BEP) according to the International Germ Cell Consensus Classification (IGCCC) prognosis group $[2,3]$.

Surgical resection is the gold standard for managing postchemotherapy residual retroperitoneal masses in advanced NSTGCT. The aim of surgery is to resect the residual retroperitoneal tumor mass (RRTM) and other residual disease localizations such as lung metastases $[4,5]$. The policy with regard to the extent of surgery for residual masses after chemotherapy is a subject of ongoing discussion with a surgical spectrum that ranges from 
excision of only visible abnormal masses [6, 7] to full bilateral retroperitoneal lymph node dissection (RPLND) $[8,9]$. Proponents of a full bilateral RPLND state that patients with advanced NSTGCT are at high risk for tumor in lymph nodes not included in modified RPLND because areas of teratoma or carcinoma are difficult to visualize intraoperatively. However, the literature confirms that modified postchemotherapy RPLND for well-defined residual masses is a safe surgical and oncologic procedure with less morbidity $[7,10]$.

After chemotherapy, mature teratoma and viable residual tumor are the main arguments for surgery. An alternative approach to surgery can be observation of patients with NSTGCT after systemic chemotherapy. Models for predicting postchemotherapy residual mass histology have been proposed to determine the patients for whom surgery should be considered [11, 12]. Noninvasive attempts have been made to predict "reliably" the viability of residual tumor tissue after chemotherapy using magnetic resonance imaging (MRI) and, more recently, positron emission tomography (PET) [13]. Nevertheless, because reliable predictions about necrosis, fibrosis, mature teratoma, or viable tumor tissue in the residual metastases cannot be made, adjuvant surgery with resection of residual disease still is indicated.

Traditionally, open full-template non-nerve-sparing RPLND was the standard practice. This approach was associated with complications related to invasive surgery, particularly damage to the sympathetic ganglia, hypogastric nerves, or postganglionic nerve fibers. These complications were responsible for sexual morbidity, mainly anejaculation and erectile disturbances [14]. Currently, the morbidity is low, and preservation of sexual and ejaculatory function is highly reliable with either a template- or nerve-sparing complete RPLND, especially in high-volume centers [15]. The median postoperative hospital stay is 6 days [16].

Higher morbidity with open RPLND and the general benefits of laparoscopy such as decreased blood loss, less pain, better cosmetic results, and a shorter postoperative hospital stay have led to the introduction of laparoscopic RPLND. On a modest scale, laparoscopic RPLND is performed primarily for the staging and possible treatment of testicular cancer, mainly in stage 1 disease [17-19]. With further refinement of laparoscopic techniques, several centers also have described the benefits of the laparoscopic procedure for stage 2 disease after completion of chemotherapy [20-26].

At the University Medical Center Groningen (UMCG), the feasibility of resecting RRTM laparoscopically was explored and evaluated as a minimally invasive surgical technique applied in the field of adjuvant surgery in the combined treatment of testicular cancer.

\section{Materials and methods}

From October 2004 to August 2007, 79 consecutive patients with disseminated NSTGCT were treated using cisplatin-based combination chemotherapy at UMCG. Before chemotherapy, the patients were staged according to the Royal Marsden classification system based on spiral computed tomographic (CT) findings of the abdomen as well as on chest and tumor marker analysis. Patients received three or four courses of BEP depending on their IGCCC classification [2, 3].

After completion of chemotherapy, when the patients had achieved complete biochemical remission (90\%), they were restaged with a spiral CT of the abdomen and chest. Of the 79 patients, $53(67 \%)$ showed a complete biochemical response with residual disease. Afterward, 45 patients $(57 \%)$ had surgery, primarily resection of a residual retroperitoneal tumor mass (RRRTM) $(51 \%)$.

Table 1 summarizes the baseline characteristics and outcome data for all 79 consecutive patients. Eight patients with residual disease and a complete response (10\%) did not undergo surgery because of extended disease in multiple organs $(n=6)$, mediastinal disease $(n=1)$, or irresectable massive retroperitoneal residual disease $(n=1)$.

Patient selection for laparoscopic RRRTM was based on the size and location of the residual tumor. Patients with a residual retroperitoneal tumor mass with a diameter smaller than $50 \mathrm{~mm}$ shown on CT and located ventrally or laterally from the aorta or vena cava were candidates for laparoscopic resection of these abnormalities. Retroperitoneal tumor masses posterior to the great vessels were not candidates for laparoscopic resection.

On the basis of these selection criteria, 29 patients with a median age of 25 years (range, 16-59 years) underwent an adjunctive laparoscopic RRRTM. The characteristics of these patients are summarized in Table 2 . The primary tumor location was in the left testicle of 16 patients (55\%) and in the right testicle of 13 patients $(45 \%)$. The median follow-up period in this study was 47 months (range, 29-70 months). During the same period, 11 patients underwent conventional laparotomy for RRRTM (Fig. 1). Eight patients had residual retroperitoneal disease too large for laparoscopic resection, and for three patients, a laparoscopic procedure was not opportune because of the tumor location.

\section{Laparoscopic procedure}

Preoperatively, no intestinal preparation was done, and no prophylactic antibiotics were administered. Laparoscopic resection was performed by experienced laparoscopic surgical oncologists. The patients were placed supine with both legs abducted in the "French" position (also called the 
Table 1 Patient baseline characteristics and outcome data for all 79 consecutive nonseminomatous testicular germ cell cancer patients with disseminated disease treated using cisplatin-based chemotherapy at the University Medical Center Groningen (UMCG) between October 2004 and August 2007

\begin{tabular}{ll}
\hline Median age: years (range) & $29(18-63)$ \\
Stage of disease according & Stage 2: $43(54)$ \\
to Royal Marsden: $n(\%)$ & Stage 3: $4(5)$ \\
& Stage 4:31 (39) \\
& Unknown: $1(1)$ \\
Prognosis (IGCCC): $n(\%)$ & \\
Good & $46(58)$ \\
Intermediate & $22(28)$ \\
Poor & $10(13)$ \\
Unknown & $1(1)$ \\
Tumor response after chemotherapy: $n(\%)$ & \\
Complete biochemical response & $71(90)$ \\
Without residual disease & $18(23)$ \\
With residual disease & $53(67)$ \\
No surgery of residual disease & $8(10)$ \\
Surgery of residual disease & $45(57)$ \\
Retroperitoneal & $40(51)$ \\
Lungs & $5(6)$ \\
No normalization of tumor markers & $5(6)$ \\
Biochemical relapse within 1 month & $1(1)$ \\
No completion of chemotherapy & $2(3)$ \\
Outcome/survival status: $n$ (\%) & $53(21-77)$ \\
No evidence of disease & $68(86)$ \\
Alive with disease & $4(5)$ \\
Died of disease & $6(8)$ \\
Died of other causes & $1(1)$ \\
Median follow-up after & \\
chemotherapy: months (range) & \\
For all 79 patients & \\
\hline & \\
& \\
&
\end{tabular}

lithotomy position) or in a half-right lateral position depending on the site of the RRTM.

In the case of a predominant pericaval residual tumor mass, the patients underwent surgery in the French position. Periaortic and left-sided masses were resected with patients in the half-right lateral position. Patients with bilateral RRTM were again placed in the French position. Pneumoperitoneum was created using an open technique, and the first 10-mm blunt tip trocar was situated paraumbilically (for the camera). Additionally, a 5-mm trocar was placed in the suprapubic region and a $10-\mathrm{mm}$ trocar in the left lower abdomen. Another 5-mm trocar was inserted into the epigastrium (Fig. 2).

Dissection was performed using the Harmonic ultrasonic cutting device (Ethicon-Endosurgery, Cincinnati, OH, USA). During the laparoscopic approach, the colon was mobilized to expose the aorta, the vena cava, or both.
The anatomic landmarks were the renal vein, the ureter, and the iliac vessels. Care was taken to avoid the lumbar vessels in the retroaortic region, with the aim to prevent autonomic nerve damage.

After exposure of the retroperitoneum and identification of the RRTM, extension of the surgical resection consisted of excising the RRTM only without unilateral dissection according to templates. An EndoCatch (Covidien, Manfield, MA, USA) was used to remove the surgical specimen. Intraoperative frozen section analysis of the specimen was not performed. No drains were used. The aim was to perform non-hand-assisted procedures. Conversion was performed when complications arose or when the surgical oncologist had the impression that the RRTM could not be removed completely using laparoscopy.

After laparoscopic resection, the patients were followed in the same manner as patients after conventional resection. A strict follow-up protocol according to European Society for Medical Oncology guidelines was carried out by the medical oncologist. This protocol included a monthly clinical assessment and tumor marker determination during the first postoperative year, followed by a gradually tapering schedule (every 2 months the second year, every 3 months the third year, every 6 months the fourth year, then annually thereafter). A CT scan of the chest and abdomen was performed in the case of clinical or biochemical signs of recurrence or for patients who were marker negative at the initial presentation of disseminated disease. Operative time, complications, transfusion rate, conversion to open surgery, and duration of hospital stay were analyzed.

\section{Results}

All 29 patients included in the laparoscopic treatment group had a biochemical complete remission after chemotherapy. Polychemotherapy elicited a reduction of the retroperitoneal metastases with a mean factor of 0.6 , resulting in a median postchemotherapy tumor size of $21 \mathrm{~mm}$ (range, 11-47 mm) (Table 2). In almost two thirds of the patients, the residual tumor was located in the lateroaortic region. The median interval between the last chemotherapy course and the laparoscopic resection of RRTM was 3 months (range, 1-6 months).

For 25 patients (86\%), the laparoscopic procedure could be conducted as planned. For 3 patients (10\%), conversion to open surgery was necessary due to slight bleeding from the common iliac artery, larger bleeding from the aorta, and the impossibility of creating a good exposure in an obese patient. In another patient (3\%), the initial plan was changed because extreme obesity prevented the creation of a window sufficiently large for laparoscopic exploration, 


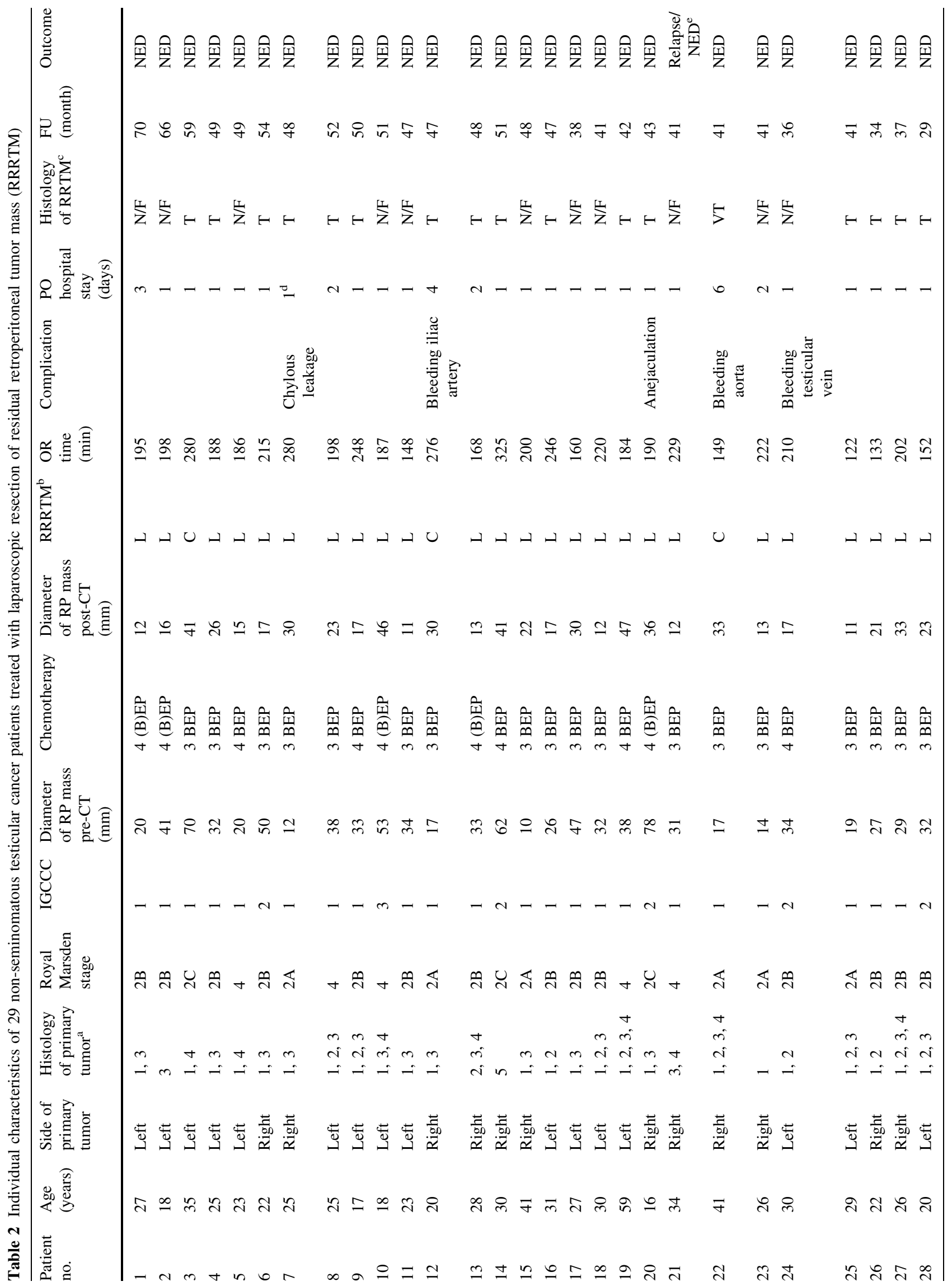



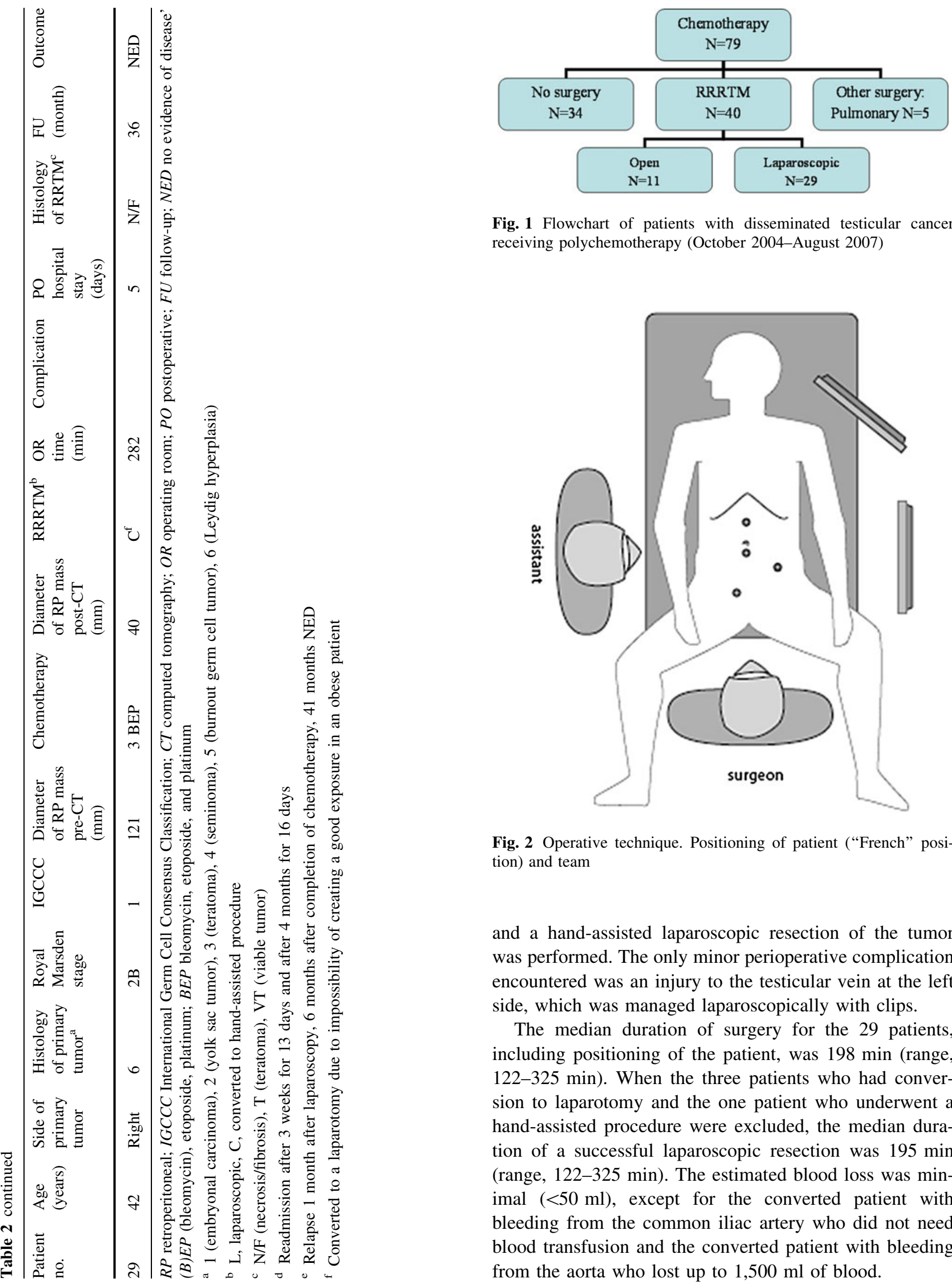

Fig. 1 Flowchart of patients with disseminated testicular cancer receiving polychemotherapy (October 2004-August 2007)

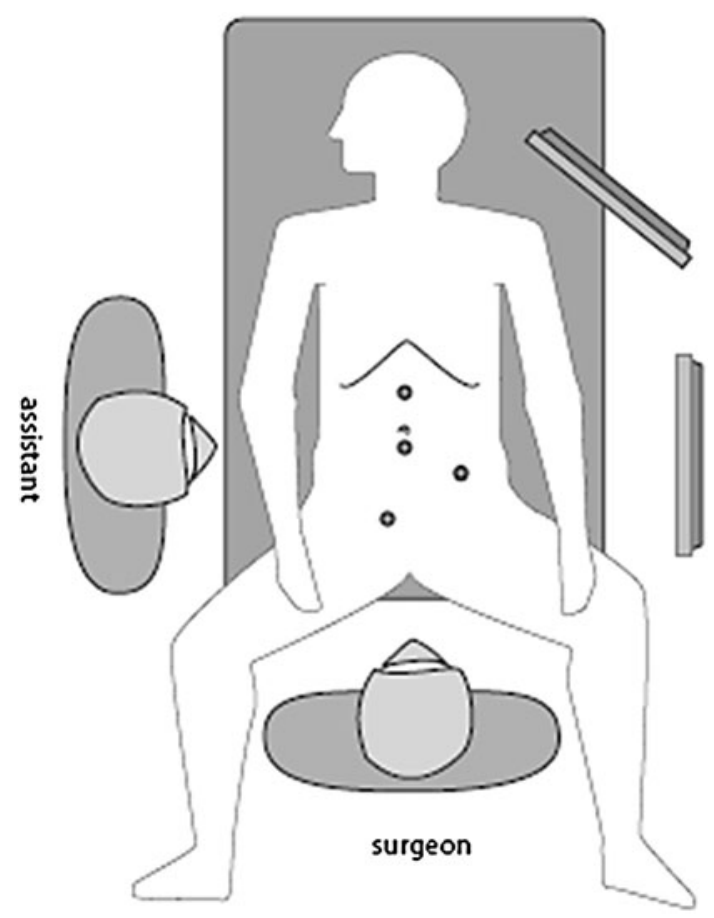

Fig. 2 Operative technique. Positioning of patient ("French" position) and team

and a hand-assisted laparoscopic resection of the tumor was performed. The only minor perioperative complication encountered was an injury to the testicular vein at the left side, which was managed laparoscopically with clips.

The median duration of surgery for the 29 patients, including positioning of the patient, was 198 min (range, 122-325 min). When the three patients who had conversion to laparotomy and the one patient who underwent a hand-assisted procedure were excluded, the median duration of a successful laparoscopic resection was $195 \mathrm{~min}$ (range, 122-325 min). The estimated blood loss was minimal $(<50 \mathrm{ml})$, except for the converted patient with bleeding from the common iliac artery who did not need blood transfusion and the converted patient with bleeding from the aorta who lost up to $1,500 \mathrm{ml}$ of blood. 
The median postoperative hospital stay was only 1 day (range, 1-6 days). The longest postoperative hospital stay (6 days) was experienced by the patient who had to undergo conversion due to injury of the aorta. During preparation of the two residual tumor masses from the aorta, a large bleeding occurred. Laparoscopy was quickly converted to a laparotomy, and the diathermic injury to the aorta was managed with two sutures. This procedure required a total operative time of $149 \mathrm{~min}$.

No postoperative infections occurred. One short-term postoperative complication (3\%) included a massive chylous ascites which could not be treated conservatively. After 4 months, laparoscopic exploration showed visible leakage from a lymph vessel, which was coagulated successfully with argon diathermia and clipped. One patient had anejaculation after laparoscopic RRRTM.

Histologic examination showed necrosis or fibrosis in 12 patients $(41 \%)$ and teratoma in 16 patients $(55 \%)$. In one patient (3\%), a radically resected viable tumor was found. Preoperatively, this patient received three courses of BEP, and after complete laparoscopic RRRTM, no additional chemotherapy courses were given.

During the median follow-up period of 47 months (mean, 46 months; range, 29-70 months), one short-term local recurrence was experienced by a 34-year-old man in the good risk prognosis group who had mature, immature teratoma and seminoma elements in his right-sided primary tumor. This man received three courses of BEP. Polychemotherapy resulted in a biochemical complete remission and was followed by a laparoscopic RRRTM. Residual tumor masses were located on the left side next to the aorta and between the aorta and the vena cava. Histology showed fibrosis. The man's tumor markers were slightly elevated 1 month after laparoscopy and 6 months after completion of chemotherapy. A CT scan showed recurrence between the aorta and the vena cava (Fig. 3). Additional polychemotherapy (paclitaxel, ifosfamide, and cisplatin) was administered, and the patient achieved a complete response, both biochemically and radiologically. A laparotomy with formal template dissection on both sides was performed. Histology of the specimen showed fibrosis. No signs of recurrence were detected 41 months after the man's last surgery.

\section{Discussion}

Laparoscopic RPLND was first described in 1992 for a patient with stage 1 NSTGCT [17]. With further development of laparoscopic techniques and experience performing them, laparoscopic RPLND was introduced in several specialized centers for the staging and treatment of mainly low-stage testicular cancer using the same boundaries of

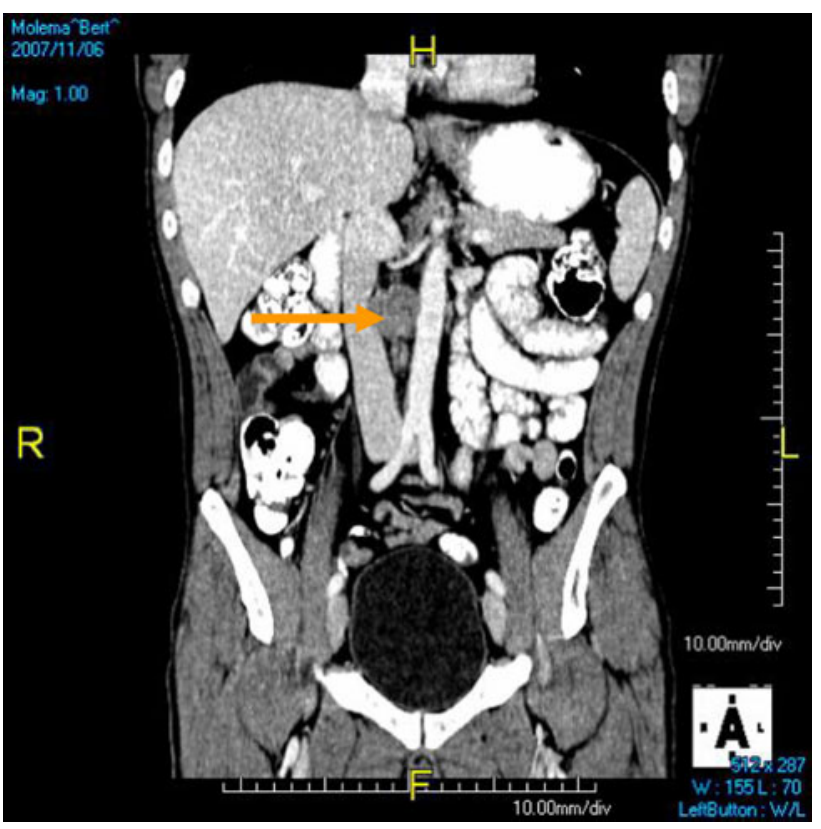

Fig. 3 Abdominal computed tomography (CT) scan of retroperitoneal recurrence

dissection as with an open approach. Table 3 summarizes the results reported by these centers [20-26]. The results show that the laparoscopic approach is feasible, with minimal morbidity, rapid recovery, and a neat cosmetic result. However, long-term oncologic results and equivalence of the conventional procedure with laparoscopic RRRTM are not fully established.

At UMCG, laparoscopic RPLND has been performed since 2005 for well-selected cases. Two thirds of the patients with RRTM appear to be candidates for laparoscopic resection RRTM.

The current study aimed to investigate our results for laparoscopic resection of RRTM, which was performed successfully for $11-$ to $47-\mathrm{mm}$ masses in 25 of the 29 selected patients. The postoperative complication rate was $7 \%$ due to postchemotherapy chylous ascites after RPLND, a not unusual complication with an incidence of $2 \%$ [27], and anejaculation experienced by one patient. The median hospital stay was 1 day. In addition, neat cosmetic results were achieved.

During the same study period, 11 patients treated at UMCG with cisplatin-based polychemotherapy for disseminated NSTGCT did not fulfill the laparoscopic inclusion criteria and were scheduled for conventional surgery consisting of laparotomy with RRRTM. The median postoperative stay for these 11 patients who underwent a laparotomy for RRTM was 6 days (range, 2-9 days), which is comparable with the median hospital stay after laparotomy reported in the 1980s [16].

As mentioned earlier, four procedures (14\%) could not be performed (completely) according to plan. The 


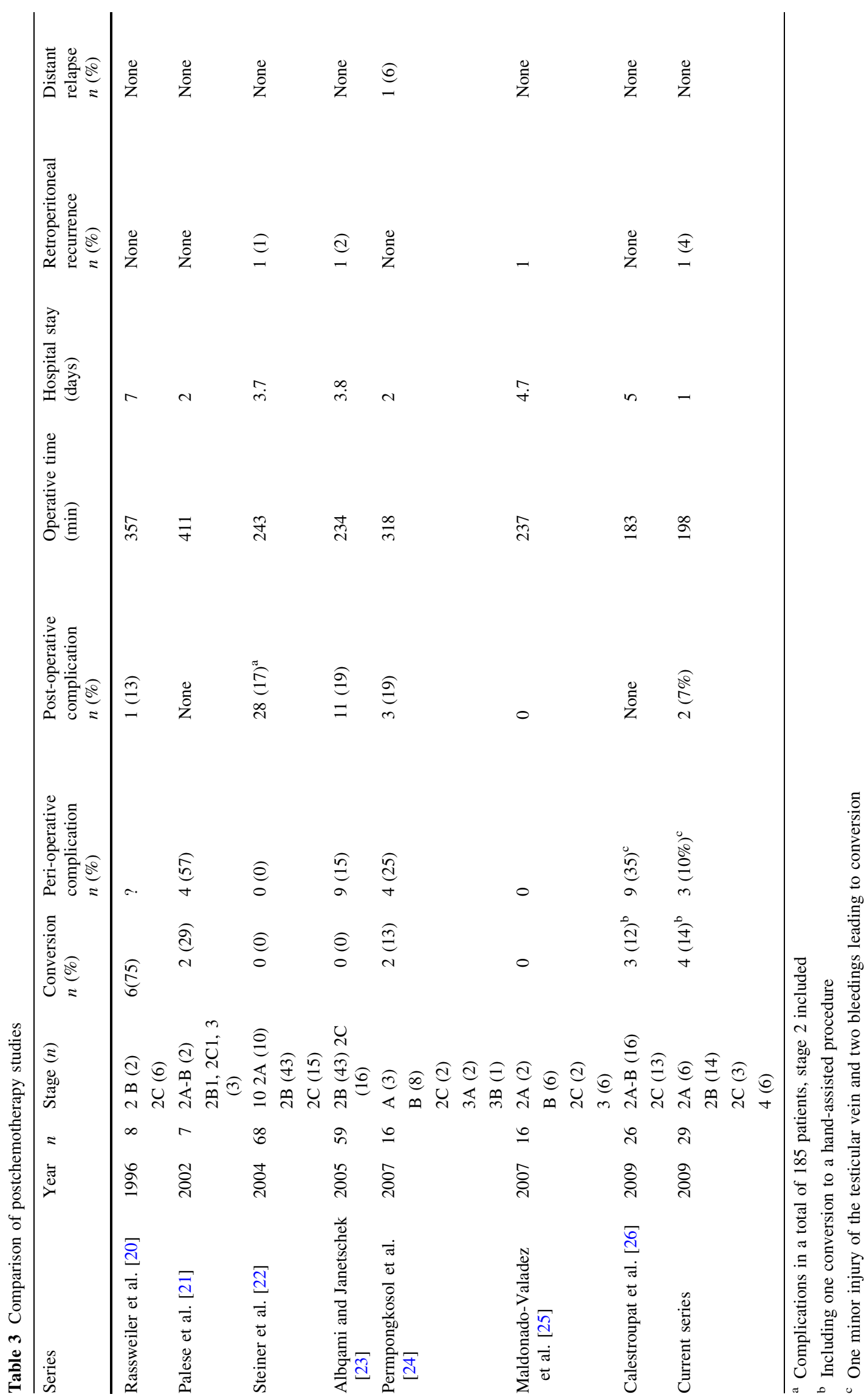


conversion rate for seven reported series varied from 0 to $75 \%$ and was $14 \%$ (4 patients) in the current series (Table 3) [20-26]. These four conversions included a nonplanned hand-assisted laparoscopic procedure and a laparotomy because of technical difficulties based on obesity of the patients. Two other conversions to a conventional laparotomy were required due to bleedings, which included one slight bleeding of the iliac artery and a larger bleeding from the aorta.

Residual retroperitoneal tumor masses are sometimes extensively attached to surrounding tissues, making a good resection extremely difficult to achieve. This can explain the occurrence of bleedings, such as the bleeding from the aorta. This risk of a bleeding possibly is higher with laparoscopic procedures than with open procedures, so adequate patient selection with evaluation of the tumor characteristics is important. In most cases, laparoscopic techniques are sufficient for handling bleedings, and conversion is not needed.

In the current study, one bleeding of the testicular vein could be managed laparoscopically. The patient was discharged from the hospital 1 day postoperatively. In another study, 9 of 59 patients (43 stage 2B, 16 stage 2C) experienced bleeding during laparoscopy not requiring conversion [23].

In the series of Steiner et al. [22], 68 patients underwent laparoscopy after two or three courses of chemotherapy without the need for any conversion. However, these authors did convert $2.4 \%$ of the stage 1 patients. These patients had not received preoperative chemotherapy.

In a small series by Rassweiler et al. [20], six (75\%) of eight patients with stage $2 \mathrm{C}$ disease who underwent postchemotherapy laparoscopy had conversion to a laparotomy because of desmoplastic reaction around the aorta and the vena cava as a result of chemotherapy [28, 29]. Permpongkosol et al. [24] had to convert procedures due to vascular injury in $2(12.5 \%)$ of 16 patients who had received three or four courses of chemotherapy (Table 3).

The median duration of the laparoscopic procedure in the current series was $198 \mathrm{~min}$, compared with 216-348 min described in literature. Furthermore, the median postoperative hospital stay was 1 day compared with median hospital stays ranging from 2 to 8.2 days in other laparoscopic series. These other series also included patients who had conversion to a laparotomy, thus explaining the discrepancy with our results.

Currently, very few institutions have reported laparoscopic RRRTM after chemotherapy for disseminated NSTGCT. Our first experience with this new technique was favorable. The minimal morbidity, the short postoperative hospital stay, and the neat cosmetic result are a step forward in the combined treatment of testicular cancer.
Although we have achieved good results over the past 30 years with conventional RRRTM, it appears that this also is possible with laparoscopic resection for patients with minimal RRTM. Approximately $70 \%$ of disseminated testicular cancer patients who require RRRTM are candidates for complete laparoscopic resection based on the current selection criteria. However, it is unknown whether the laparoscopic procedure will result in more frequent (short or late) relapses. In the current series, one patient (4\%) had a short-term relapse. The recurrence was located between the vena cava and the aorta. Preoperative CT scan images showed an RRTM located on the left side of the aorta between the aorta and vena cava. Although this RRTM was resected during laparoscopy, residual tissue remained behind, causing outgrowth of viable tumor. This relapse can be calculated as a technical failure. Short- and long-term relapses after chemotherapy are mostly related to incomplete resection of residual disease and also are encountered after conventional surgery [30].

The limitation of this study is that the oncologic efficacy of the procedure remains questioned because the long-term oncologic follow-up data are not equivalent to those for the open procedure. In the future, after more patients have been treated with laparoscopic resection, data will become available with reliable relapse figures. This potential pitfall requires prolonged and very stringent follow-up assessment to monitor the oncologic safety of the laparoscopic resection of RRTM. It is important to perform thorough followup assessment to be certain that a minimally invasive intervention does not involve the risk of so-called extratemplate disease [31].

An overshadowing component of our study is the controversy surrounding the surgical management of patients with NSTGCT and concerns about the development of laterelapsing abdominal teratoma [29]. Late-recurring disease is characterized by slow growth, production of alphafetoprotein, chemoresistance, and a poor prognosis [28]. Our surgical management of patients with NSTGCT conforms to the European guidelines for testicular cancer [27].

Although our results and those of others are favorable, questions remain: Is laparoscopic RRRTM as complete oncologically as an open procedure? How long should we wait before laparoscopic RRRTM is proclaimed as the standard, or should a randomized study be performed? Particularly the rapid postoperative recovery, the low morbidity, and the neat cosmetic results contribute to the well-being of the usually young patients, most of whom still have many years ahead of them. Whatever policy is chosen for the treatment of patients with advanced NSTGCT, management should take place at a referral center with specific expertise in the treatment of testicular cancer and an oncologic team of specialists. 


\section{Conclusion}

Laparoscopic RRRTM after chemotherapy for disseminated testicular cancer is a feasible surgical treatment option with a short hospital stay and neat cosmetic results for well-selected patients. Which patients are the right candidates for laparoscopic RRRTM remains the question. Close and long-term follow-up assessment of long-term results with respect to tumor recurrence is obligatory.

Disclosures Çiğdem Öztürk, Robert J. van Ginkel, Ruby M. Krol, Jourik A. Gietema, Hendrik S. Hofker, and Harald J. Hoekstra have no conflicts of interest or financial ties to disclose.

Open Access This article is distributed under the terms of the Creative Commons Attribution Noncommercial License which permits any noncommercial use, distribution, and reproduction in any medium, provided the original author(s) and source are credited.

\section{References}

1. Sonneveld DJ, Hoekstra HJ, van der Graaf WT, Sluiter WJ, Mulder NH, Willemse PH et al (2001) Improved long-term survival of patients with metastatic nonseminomatous testicular germ cell carcinoma in relation to prognostic classification systems during the cisplatin era. Cancer 91:1304-1315

2. International Germ Cell Cancer Collaborative Group (1997) International Germ Cell Consensus Classification: a prognostic factor-based staging system for metastatic germ cell cancers. J Clin Oncol 15:594-603

3. Huddart RA (2007) Testicular seminoma: ESMO clinical recommendations for diagnosis, treatment, and follow-up. Ann Oncol 18(Suppl 2):ii40-ii41

4. Oldenburg J, Alfsen GC, Lien HH, Aass N, Waehre H, Fossa SD (2003) Postchemotherapy retroperitoneal surgery remains necessary in patients with nonseminomatous testicular cancer and minimal residual tumor masses. J Clin Oncol 21:3310-3317

5. Kesler KA, Kruter LE, Perkins SM, Rieger KM, Sullivan KJ, Runyan ML, Brown JW, Einhorn LH (2011) Survival after resection for metastatic testicular nonseminomatous germ cell cancer to the lung or mediastinum. Ann Thorac Surg 91:1085-1093

6. Ozen H, Ekici S, Sozen S, Ergen A, Tekgül S, Kendi S (2001) Resection of residual masses alone: an alternative in surgical therapy of metastatic testicular germ cell tumors after chemotherapy. Urology 57:323-327

7. Rabbani F, Goldenberg SL, Gleave ME, Paterson RF, Murray N, Sullivan LD (1998) Retroperitoneal lymphadenectomy for postchemotherapy residual masses: is a modified dissection and resection of residual masses sufficient? Br J Urol 81:295-300

8. Carver BS, Cronin AM, Eggener S, Savage CJ, Motzer RJ, Bajorin D, Bosl GJ (2010) The total number of retroperitoneal lymph nodes resected impacts clinical outcome after chemotherapy for metastatic testicular cancer. J Urol 75:1431-1435

9. Large MC, Sheinfeld J, Eggener SE (2009) Retroperitoneal lymph node dissection: reassessment of modified templates. BJU Int 104:1369-1375

10. Heidenreich A, Pfister D, Witthuhn R, Thüer D, Albers P (2009) Postchemotherapy retroperitoneal lymp node dissection in advanced testicular cancer: radical of modified template resection. Eur Urol 55:217-224
11. Steyerberg EW, Keizer HJ, Fosså SD, Sleijfer DT, Toner GC, Schraffordt Koops H, Mulders PF, Messemer JE, Ney K, Donohue JP et al (1995) Prediction of residual retroperitoneal mass histology after chemotherapy for metastatic nonseminomatous germ cell tumor: multivariate analysis of individual patient data from six study groups. J Clin Oncol 13:1177-1187

12. Vergouwe Y, Steyerberg EW, Foster RS, Sleijfer DT, Fosså SD, Gerl A, de Wit R, Roberts JT, Habbema JD (2007) Predicting retroperitoneal histology in postchemotherapy testicular germ cell cancer: a model update and multicentre validation with more than 1000 patients. Eur Urol 51:424-432

13. Oechsle K, Hartmann M, Brenner W, Venz S, Weissbach L, Franzius C et al (2008) [18F]Fluorodeoxyglucose positron emission tomography in nonseminomatous germ cell tumors after chemotherapy: the German multicenter positron emission tomography study group. J Clin Oncol 26:59305935

14. van Basten JP, Jonker-Pool G, Van Driel MF, Sleijfer DT, van der Wiel HB, Hoekstra HJ (1995) The sexual sequelae of testicular cancer. Cancer Treat Rev 21:479-495

15. Pettus JA, Carver BS, Masterson T, Stasi J, Sheinfeld J (2009) Preservation of ejaculation in patients undergoing nerve-sparing postchemotherapy retroperitoneal lymph node dissection for metastatic testicular cancer. Urology 73:328-331

16. Gelderman WA, Schraffordt Koops H, Sleijfer DT, Oosterhuis JW, Van der Heide JN, Mulder NH et al (1988) Results of adjuvant surgery in patients with stage III and IV nonseminomatous testicular tumors after cisplatin-vinblastine-bleomycin chemotherapy. J Surg Oncol 38:227-232

17. Rukstalis DB, Chodak GW (1992) Laparoscopic retroperitoneal lymph node dissection in a patient with stage 1 testicular carcinoma. J Urol 148:1907-1909

18. Bhayani SB, Ong A, Oh WK, Kantoff PW, Kavoussi LR (2003) Laparoscopic retroperitoneal lymph node dissection for clinical stage I nonseminomatous germ cell testicular cancer: a long-term update. Urology 62:324-327

19. Nielsen ME, Lima G, Schaeffer EM, Porter J, Cadeddu JA, Tuerk I, Kavoussi LR (2007) Oncologic efficacy of laparoscopic RPLND in treatment of clinical stage I nonseminomatous germ cell testicular cancer. Urology 70:1168-1172

20. Rassweiler JJ, Seemann O, Henkel TO, Stock C, Frede T, Alken P (1996) Laparoscopic retroperitoneal lymph node dissection for nonseminomatous germ cell tumors: indications and limitations. J Urol 156:1108-1113

21. Palese MA, Su LM, Kavoussi LR (2002) Laparoscopic retroperitoneal lymph node dissection after chemotherapy. Urology 60:130-134

22. Steiner H, Peschel R, Janetschek G, Holtl L, Berger AP, Bartsch $\mathrm{G}$ et al (2004) Long-term results of laparoscopic retroperitoneal lymph node dissection: a single-center 10-year experience. Urology 63:550-555

23. Albqami N, Janetschek G (2005) Laparoscopic retroperitoneal lymph node dissection in the management of clinical stage I and II testicular cancer. J Endourol 19:683-692

24. Permpongkosol S, Lima GC, Warlick CA, Allaf ME, Varkarakis IM, Bagga HS et al (2007) Postchemotherapy laparoscopic retroperitoneal lymph node dissection: evaluation of complications. Urology 69:361-365

25. Maldonado-Valadez R, Schilling D, Anastasiadis AG, Sturm W, Stenzl A, Corvin S (2007) Postchemotherapy laparoscopic retroperitoneal lymph node dissection in testis cancer patients. J Endourol 21:1501-1504

26. Calestroupat JP, Sanchez-Salas R, Cathelineau X, Rozet F, Galiano M, Smyth G et al (2009) Postchemotherapy laparoscopic retroperitoneal lymph node dissection in nonseminomatous germ cell tumor. J Endourol 23:645-650 
27. Evans JG, Spiess PE, Kamat AM, Wood CG, Hernandez M, Pettaway CA et al (2006) Chylous ascites after postchemotherapy retroperitoneal lymph node dissection: review of the $\mathrm{M}$. D. Anderson experience. J Urol 176(4 Pt 1):1463-1467

28. Shahidi M, Norman AR, Dearnaley DP, Nicholls J, Horwich A, Huddart RA (2002) Late recurrence in 1263 men with testicular germ cell tumors. Multivariate analysis of risk factors and implications for management. Cancer 95:520-530

29. Baniel J, Foster RS, Gonin R, Messemer JE, Donohue JP, Einhorn LH (1995) Late relapse of testicular cancer. J Clin Oncol 13: $1170-1176$
30. Sharp DS, Carver BS, Eggener SE, Kondagunta GV, Motzer RJ, Bosl GJ et al (2008) Clinical outcome and predictors of survival in late relapse of germ cell tumor. J Clin Oncol 26:5524-5529

31. Carver BS, Shayegan B, Eggener S, Stasi J, Motzer RJ, Bosl GJ et al (2007) Incidence of metastatic nonseminomatous germ cell tumor outside the boundaries of a modified postchemotherapy retroperitoneal lymph node dissection. J Clin Oncol 25: 4365-4369 